\title{
Analysis of Risk Associated with Hospital Waste Management Practices in Public Hospitals in Port Harcourt
}

\author{
Chukwu Okeah GO1*, Abel JB ${ }^{2}$ and Okemini $\mathrm{EB}^{3}$ \\ ${ }^{1}$ Department of Geography \& Environmental Management, University of Port Harcourt, Nigeria \\ ${ }^{2}$ River State Ministry of Environment, Nigeria \\ ${ }^{3}$ Department of Sociology, University of Port Harcourt, Nigeria
}

Received: March 19, 2018; Published: 跮 March 28, 2018

*Corresponding author: Chukwu Okeah GO, Department of Geography \& Environmental Management, University of Port Harcourt, Nigeria, Email: gift.chukwuokeah@uniport.edu.ng

\begin{abstract}
The study set out to investigate the risk associated with hospital waste management in Port Harcourt. To achieve this, five research questions and five research objectives alongside two hypotheses were put forth to guide the study. The study adopted the use of cross sectional survey research design. A total of 90 persons were purposively sampled from three public hospitals using the stratified sampling technique to ensure all the class of persons working in the hospital was captured in the study. Questionnaire was used as the data collection instrument in the study. The results from the study revealed that waste is generated often in the sampled hospitals, Liquids, human waste and sharps are the most generated waste in the hospitals, the major waste disposal method amongst the hospitals is the use of waste contractors and that the health risk associated with hospital waste is high.

Statistically the study revealed that the study revealed that there is no impact of personnel training on hospital waste management and also that there are health risks associated with Hospital waste management system. Therefore the study recommended that there is need to expose the workforce to more trainings that have true bearing on waste management as to enhance their knowledge of waste management making them fit in the job they do and that Government needs to enshrine a law set up a check system for hospital waste management system as the use of waste contractors as revealed is unsuitable for hospital waste management.
\end{abstract}

Keywords: Risk; Hospital waste; Waste management practices; Public hospitals; Health

\section{Introduction}

Medical waste management as observed by Aseweh (2007) has heightened the level of environmental damage in recent time. The health risk and implication on the workers is revolving. Technological advancement and innovation in health care domain and substantial increase in establishment of new health care centres has increased the quantity of waste generated that is potentially hazardous to health and mans living environment. Some of the risk as stated by Emad [1] is exposure of health workers, waste handlers and the environment wherein the public are exposed to hazardous waste such as mercury, expired pharmaceuticals and general waste. By definition, waste is any substance either in liquid, solid or gaseous state, left over that is attributed to any definite person or organism responsible for it. According to (Ekpor, 2009), any worthless object, substance that is detective and has no further value that to be disposed is classified as a waste. The quantity of waste generated by the activities of the health care centre has gone so high overtime due to rapid utilization spreading across the urban and rural settlements with the attendant increase on hospital, clinics, medical establishments and the waste generated if not properly managed posses' potential risks to the human's life and the environment.

According to Baveja, Murallidhar and Aggaval [2], medical waste that is generated in the process of health care delivery are human tissues, sharps body parts and infecting materials that are environmentally unfriendly. Some of developing nations of the world are not aware of the huge risks inherent with poor hospital 
waste handling and management. Port Harcourt city, South-South region of Nigeria, there is paucity in the knowledge of the hazardous nature of medical waste to humans and the environment as this is evidenced in the activities of waste scavenges, who ravage the sites of hospital waste dumps in search of used clothing to be sold as rags, and other metals, polythene for recycling purposes. Thus enacting the policy of waste to wealth in a highly polluted and hazardous environment that can endanger health of these scavengers and also the health of the final consumers is a serious challenge with high detrimental effects.

Akinwale [3] asserted that lack of enabling policy and awareness campaigned regarding the health risks and health care facilities, environmental pollution of hospital waste. According to Akinwale [3], is a reflection on the attitude of citizenry towards hospital waste handling. Khanehzae et al. [4], remarked in their contribution that all individuals dealing with hospital waste are potential at risk not excluding nurses and other health care staff. In their contribution, Oli et al. [5] stated that exposure to hazardous medical waste could lead to series of health challenges such as infection, infertility, genital deformities, cancer [6], dermatitis, typhoid, asthma, hepatitis, HIV. Environmental and health risks associated with hospital generated waste can be reduced through effective planning and efficient policy. Twinch [7], noted that handling and disposal of medical waste methods requires a lot of carefulness, safety approach is important as they are hazardous in nature, infections and has unpleasant odour.

It is of great importance to note that inappropriate handling and disposal of hospital waste poses even greater danger and threat to the environment even than before. Hospital management should make provision for adequate waste handling and disposal methods to reduce health risks and environmental pollution. Proper waste segregation is paramount at production point to avoid hazardous waste contaminating non hazardous as it possess health associated risks to hospital workers, general public, the environment. As Port Harcourt population is increasing and sprawl of hospitals and clinic, and health care facilities are on the rise, it is obvious that more hospital waste are generated and the need for effective hospital waste management system policy put in place.

Most of environmental problems like air, water and land pollution are as a result of improper hospital waste disposal. Biological, radioactive and chemicals from health care facilities that are improperly handled or disposed one a major cause of environmental and health risks. It is important that at different points of their waste, generation, collection, storage, transport and treatment that proper personal protective equipment (PPE) is used. Some practices like manual transport foe longer distance use of uncovered containers, exposure times beyond acceptable limits, lack of workers and equipments should be discouraged. W.H.O [7], noted that medical staff, health handling workers and the surrounding environment are exposed to toxic and health risks if the hospital waste are improperly managed and disposed due to their hazardous nature. When wastes are indiscriminately dumped in municipal dustbins, open spaces and water bodies, etc. the general public health is endangered and this can aggregate outbreak and spread of diseases. Hospital management attitude towards handling of hazardous waste, its effect on humans and the environment vary from one health institutions to another.

\section{Methodology}

To determine the sample for the study, the non probability sampling technique was adopted under this method, the purposive sampling procedure was chosen for the study. The choice of the purposive sampling technique arose from the fact that most of the hospitals may not be willing to give full information on its staff strength across the different hospitals even though it is a public owned hospital. Hence the researcher deemed it fit to adopt this technique since it allowed the research to use subjective choice. The study adopted the use of three (3) public owned hospitals in the city of Port Harcourt which constituted the population for the study. To determine the sample size for the study, the researcher purposefully selected 30 persons per hospital which brought to a total of 90 persons.

The selection of the thirty persons per hospital was stratified as to ensure that the different class of people in the Hospital was capture and represented due to the nature of the study. Hence the classes identified were, Medical Doctors and Nurses, Cleaners and waste contractors. The study adopted the use of questionnaires as the instrument for data collection. This was administered to persons in the category of Medical Doctors and Nurses, Cleaners and waste contractors in the sampled hospitals in a random manner.

\section{Results and Discussions}

\section{Knowledge of waste generation in hospitals}

Knowledge of waste generation in the hospital showed that $100 \%$ of the respondents have good knowledge of waste generation in the sampled hospital for this study. This is as shown in table 1 below.

Table 1: Awareness of Waste Generation in the Hospitals.

\begin{tabular}{|c|c|c|}
\hline \multirow{2}{*}{ Response } & \multicolumn{2}{|c|}{ Frequency } \\
\cline { 2 - 3 } & No & $\%$ \\
\hline Aware & 90 & 100 \\
\hline Not aware & - & - \\
\hline Total & 90 & 100 \\
\hline
\end{tabular}

\section{Extent of waste generated}

The extent of waste generation in this context tries to ascertain how much waste is generated so as to determine the implication on the study environment. From the report $66.7 \%$ of the respondents agreed that to them, waste is generated very often, $21.1 \%$ of the 
respondents stated that waste are often generated and $12.2 \%$ of the study population stated that waste are rarely generated (Table 2).

Table 2: Extent of Waste Generated.

\begin{tabular}{|c|c|c|}
\hline \multirow{2}{*}{ Response } & \multicolumn{2}{|c|}{ Frequency } \\
\cline { 2 - 3 } & No & \% \\
\hline Very often & 60 & 66.7 \\
\hline Often & 19 & 21.1 \\
\hline Rarely & 11 & 12.2 \\
\hline Total & 90 & 100 \\
\hline
\end{tabular}

\section{Types of waste generated}

Types of wasted generated in the hospitals shows that $13.3 \%$ are general waste, $23.3 \%$ of them are sharps, $20 \%$ of the waste are cultures and stock, pathological waste accounts for $8.90 \%$ while liquid, human or animal waste accounts for $34.5 \%$ of the total waste generated, showing that it is more predominate than the other classes of waste. This is as shown in Table 3 below.

Table 3: Types of Waste Generated.

\begin{tabular}{|c|c|c|}
\hline \multirow{2}{*}{$\begin{array}{c}\text { Types of Waste } \\
\text { Generated }\end{array}$} & No & Frequency \\
\cline { 2 - 3 } & 12 & 13.3 \\
\hline General waste & 21 & 23.3 \\
\hline Sharps & 18 & 20 \\
\hline Cultures \& stock & 8 & 8.9 \\
\hline Pathological waste & 31 & 34.5 \\
\hline $\begin{array}{c}\text { Liquid, Human or } \\
\text { Animal waste }\end{array}$ & 90 & 100 \\
\hline Total & & \\
\hline
\end{tabular}

\section{Waste disposal method}

Table 4 reveals the method of waste disposal in each of the selected hospitals for the study, 14 respondents representing $15.6 \%$ stated that deep burial method is used, 12 respondents representing $13.3 \%$ of the total study population agreed to waste burning as a method, 39 respondent representing $43.3 \%$ agreed to the use of dump site or contractors, 25 respondents $27.8 \%$ stated that incineration are used. Autoclave method as revealed is alien to all the respondents. This is as shown in Table 5 below

Table 4: Waste Disposal Method.

\begin{tabular}{|c|c|c|}
\hline \multirow{2}{*}{ Waste Disposal Methods } & \multicolumn{2}{|c|}{ Total } \\
\cline { 2 - 3 } & No & $\%$ \\
\hline Deep Burial & 14 & 15.6 \\
\hline Burning & 12 & 13.3 \\
\hline Incineration & 25 & 27.8 \\
\hline Autoclave & - & \\
\hline Private & & \\
\hline Dump site or Waste contractor & 39 & 43.2 \\
\hline
\end{tabular}

\begin{tabular}{|c|c|c|}
\hline Total & 90 & 100 \\
\hline
\end{tabular}

\section{Awareness of waste management practices}

As revealed on Table 5, the total respondents for the study have knowledge of waste management practices this accounts for a $100 \%$ response. This is as shown in table 4 below.

Table 5: Awareness of Waste Management Practices.

\begin{tabular}{|c|c|c|}
\hline \multirow{2}{*}{ Response } & \multicolumn{2}{|c|}{ Frequency } \\
\cline { 2 - 3 } & No & \% \\
\hline Aware & 90 & 100 \\
\hline Often & - & - \\
\hline Total & 90 & 100 \\
\hline
\end{tabular}

\section{Waste audit awareness}

The knowledge of waste audit awareness by the people showed that $64.4 \%$ of the respondents are aware of audit practices while $35.6 \%$ are not aware. This is as shown in Table 6 below.

Table 6: Waste Audit Awareness.

\begin{tabular}{|c|c|c|}
\hline \multirow{2}{*}{ Response } & \multicolumn{2}{|c|}{ Frequency } \\
\cline { 2 - 3 } & No & \% \\
\hline Aware & 58 & 64.4 \\
\hline Not Aware & 32 & 35.6 \\
\hline Total & 90 & 100 \\
\hline
\end{tabular}

\section{Extent of staff training on waste management}

The extent of staff training in waste management, handling and disposal from the report, $58.8 \%$ of the respondents agreed that to them the extent of training received by staff in waste handling and management is very good, $20 \%$ of the respondents stated that it is good, $14 \%$ of the respondents agreed that it is fair while $5.8 \%$ of the respondents agreed that training of staff on waste management, handling and disposal is poor. This is as shown in Table 7

Table 7: Extent of Staff Training on Waste Management.

\begin{tabular}{|c|c|c|}
\hline \multirow{2}{*}{ Response } & \multicolumn{2}{|c|}{ Frequency } \\
\cline { 2 - 3 } & No & \% \\
\hline Very good & 53 & 58.8 \\
\hline Good & 18 & 20 \\
\hline Fair & 13 & 14.4 \\
\hline Very poor & 6 & 5.8 \\
\hline Total & 90 & 100 \\
\hline
\end{tabular}

\section{Risks associated with hospital waste}

On the area of risk associated with hospital waste in the study area, 75 respondents of the total population representing $80 \%$ of the total population reported that the risk associated with hospital waste is very high, 12 respondents out of the total study population representing $13.3 \%$ of the total population said it is very low, 
2 respondents representing $2.3 \%$ of the total study population agreed that the impacts is very low, non for moderate risk and 1 respondent representing $1.1 \%$ of the total study population agreed that the risk is low. This is as shown in Table 8 below;

Table 8: Health Risk associated with Hospital Waste.

\begin{tabular}{|c|c|c|}
\hline Response & Frequency & Percentage \% \\
\hline Very high & 75 & 80.0 \\
\hline High & 12 & 13.3 \\
\hline Very low & 2 & 2.3 \\
\hline Moderate & - & - \\
\hline Low & 1 & 1.1 \\
\hline Total & 90 & 100 \\
\hline
\end{tabular}

\section{Use of personal protective equipment in waste handling}

From Table 9 below it is observed that out of 90 respondents in the use of coverall 12 respondents agreed that they use coverall always, 40 respondents use it not very often and 35 respondents use it once in a while In the case of safety boot only 21 respondents use it always, 28 respondents use it not very often while 41 respondents use it once in a while. The table also reports that on the use of hand glove, 19 respondents use it always, 17 respondents use it not very often while 54 respondents use it once in a while. Use of helmet as revealed, showed that 32 respondents agreed that the use helmet always, 31 respondents agreed that they do not use it very often while 27 respondents stated that they use it once in a while. Lastly, on the use of nose mask, 6 respondents agreed that they use it always, 56 respondents stated that the use not very often and 28 respondents agreed that they use it once in a while. This is as shown on Table 9 below.

Table 10: Hospital Waste and Health Implications.
Table 9: Use of Personal Protective Equipment in Waste Handling.

\begin{tabular}{|c|c|c|c|}
\hline \multirow{2}{*}{$\begin{array}{c}\text { Types of PPE } \\
\text { in use }\end{array}$} & \multicolumn{3}{|c|}{ Frequency of Use } \\
\cline { 2 - 4 } & Always & Not very often & Once in a while \\
\hline Coverall & 12 & 43 & 35 \\
\hline Safety Boot & 21 & 28 & 41 \\
\hline Hand glove & 19 & 17 & 54 \\
\hline Helmet & 32 & 31 & 27 \\
\hline Nose mask & 6 & 56 & 28 \\
\hline
\end{tabular}

\section{Hospital waste and health implications}

Table 10 shows hospital waste and its health implication for waste handlers and others who are associated with the waste management, from the analysis, it is observed that on the kinds of illness suffered, 70 of the respondents representing $77.8 \%$ of the study population consented that they have suffered catarrh while only 20 respondents representing $22.2 \%$ of the study population stated that they have not had catarrh within the period under review. The table reveals that 62 respondents representing $68.8 \%$ of the study population have suffered cough while 28 respondents representing $31.2 \%$ stated that they have not had any case of cough. Heart ache as revealed, shows that only 62 respondents representing $68.8 \%$ of the study population have suffered it while 28 respondents representing $31.2 \%$ stated that they have not had any case of heart ache.

In the case of skin rashes, 67 respondents representing $74.4 \%$ of the study population have suffered skin rashes while 13 respondents representing $25.6 \%$ stated that they have not had any case of rashes.

\begin{tabular}{|c|c|c|c|c|c|c|c|c|c|c|c|c|}
\hline \multicolumn{5}{|c|}{ Kind of illness Suffered } & \multicolumn{4}{|c|}{ Record of Lungs Related illness } & \multicolumn{4}{|c|}{ Record of Cancer/Heart Related Illness } \\
\hline & Yes & $\%$ & No & $\%$ & Yes & $\%$ & No & $\%$ & Yes & $\%$ & No & $\%$ \\
\hline Catarrn & 70 & 77.8 & 20 & 22.2 & & & & & & & & \\
\hline Cough & 62 & 68.8 & 28 & 31.2 & 68 & 75.5 & 22 & 24.5 & 77 & 85.5 & 13 & 14.5 \\
\hline Heart ache & 62 & 68.8 & 28 & 31.2 & & & & & & & & \\
\hline $\begin{array}{c}\text { Skin } \\
\text { Rashes }\end{array}$ & 67 & 74.4 & 13 & 25.6 & & & & & & & & \\
\hline $\begin{array}{l}\text { Breathing } \\
\text { difficulty }\end{array}$ & 80 & 88.8 & 10 & 11.1 & & & & & & & & \\
\hline
\end{tabular}

Lastly, difficulty in breathing as revealed on the table has been experienced by a large number of the respondents. 80 of the respondents representing $88.8 \%$ of the study population have had cases of breathing difficulties while 10 respondents representing $11.1 \%$ have not had any of such case. Lungs related illness shows that $75.5 \%$ of the study population has suffered it and in the case of cancer/heart related illness, $85.5 \%$ of the study population has suffered from it. See Table 10 below.

\section{a. Hypothesis Testing}

The following hypotheses were tested; i. There is no statistically significant impact of personnel training on hospital waste management

ii. There is no health risk associated with Hospital waste Management system

The above stated hypotheses were tested using the Chi-Square statistical tool.

a. Hypothesis One: There is no statistically significant impact of personnel training on hospital waste management.

The Chi-Square value as shown on appendix 1 is $\mathrm{X}^{2}=5.728$ 


$$
\mathrm{df}=(\mathrm{r}-1)(\mathrm{C}-1)
$$$$
(3-1)(4-1)=6
$$

Hence, $\mathrm{df}=6$

$\mathrm{X}^{2}$ critical value at 95\% significance level is 12.592 .

Decision: Since the Chi- square calculated value of 5.728 is less than the critical value of 12.592 at $95 \%$ significance level, we therefore accept the null hypothesis of no statistical significant impact of personnel training on hospital waste management and reject the alternate hypothesis of significant impact of personnel training on hospital waste management in Port Harcourt.

b. Hypothesis Two: There is no health risk associated with Hospital waste Management system

The Chi-Square value as shown on appendix 1 is $\mathrm{X}^{2}=25.882$

$$
\mathrm{df}=(\mathrm{r}-1)(\mathrm{C}-1)
$$

$$
(3-1)(5-1)=8
$$

Hence, $\mathrm{df}=8$

$\mathrm{X}^{2}$ critical value at $95 \%$ significance level is 15.507 .

Decision: Since the Chi- square calculated value of 25.882 is greater than the critical value of 15.507 at $95 \%$ significance level, we therefore reject the null hypothesis of no health risks associated with Hospital waste Management system and accept the alternate hypothesis of which states that there are health risks associated with Hospital waste management systems.

\section{Discussion of Findings}

This study set out to investigate the health risk associated with hospital waste management with intent to mitigate the health risk. The study also examined the pattern of waste disposal and management in Port Harcourt hospitals, assess the facilities for waste disposal in hospitals, examine the effect of training of the personnel handling hospital waste on hospital waste management, ascertain the health risk associated with hospital waste management in Port Harcourt and determine compliance to use of Personal Protective Equipment in Hospital waste management. The findings of the study revealed that the people in the sampled hospitals have good knowledge of waste generation. And that waste generation as reported by $66.7 \%$ of the total respondents showed that the generation of waste in the hospitals was very often.

The study also revealed that on the type of waste generated in the hospitals, five classes were identified but that liquid, human or animal waste was the most generated and this accounts for $34.5 \%$ of the total waste generated, this if followed by sharps which accounts for $23.3 \%$ of the total respondents consent.

On the awareness of waste management practices, the study revealed that the whole respondents in the study are aware of waste management practices. The findings of the study also revealed that on the method of waste disposal adopted the use of waste contractors was the most prevalent method used by the respondents in the different hospitals this was followed by the use of incinerator which is supported by $27.8 \%$ of the total respondents. Waste auditing as revealed was also acknowledge by the respondents who stated that from time to time waste auditors visited the hospitals to audit their waste management processes.

The study revealed that the level of training given to the staff of the hospitals was very good this was as reported by $58.8 \%$ of the total study population. This therefore implies that the personnel in the hospitals were open to trainings on waste handling and management as a way of reducing the health risk Implications. This agrees with the findings of Igwe (2016) which states that training and re training of welders on occupational hazards is a major tool for risk reduction and the creation of an accident free operation. On the health risk associated with hospital waste management, $80 \%$ of the study population stated that it is very high. This is due to the extent of exposure and contact to toxic material that have the potentials to cause serious harm to both man and the environment.

This finding also agrees with the work of Nwanosike [8] which stated that exposure to hazards has grievous negative impacts on human health. This was further supported by Antonini, [9] who stated that exposure to waste causes respiratory effects such as pulmonary functions, Asthma, fume fever, Bronchitis, Pneumoconiosis and Fibrosis, Respiratory Infection and Immunity and lungs cancer. On the use of personal protective equipment, the study revealed that on the overall, less than half of the respondents for all the stated PPE used them always as a tool for reducing the exposure to hazards. Finally, the hospital waste and health implication revealed that most of the respondents agreed that they have been exposed to one illness or the other due to their occupation as waste handlers. It also revealed that on a large scale, Lungs related illness shows that $75.5 \%$ of the study population has suffered it and in the case of cancer/heart related illness, $85.5 \%$ of the study population has suffered from it. This agrees with Igwe [10]. Statistically, the study revealed that there is no impact of personnel training on hospital waste management and also that there are health risks associated with Hospital waste management system.

\section{Conclusion and Recommendations}

The priority of any health institution is the care of patients. Its policy has been oriented traditionally to the health and well being of patients, which has less relevance to environmental problems. However, it is essential that hospitals be concerned with environmental protection otherwise, a vicious circle of disease derived from inadequate waste management could be created with devastating effects to workers in charge of this task, the hospital community and the population in general.

In a nutshell, incorporating environmental management into the running of a hospital is essential for improving standards in 
health institutions along with increasing efficiency, satisfying requirement and reducing cost. Arising from the above the following recommendations are made;

a. There is need to upgrade existing waste management policies in the hospitals to meet the present day realities.

b. There is need to expose the workforce to more trainings that have true bearing on waste management as to enhance their knowledge of waste management making them fit in the job they do.

c. Provision and effective monitoring of workers use of PPE is necessary to reduce health risk posed by their exposure to hospital waste.

d. Government needs to enshrine a law to set up a check system for hospital waste management system as the use of waste contractors as revealed is unsuitable for hospital waste management.

\section{References}

1. Wonodi C (2016) Analysis of wetland dynamics in Port Harcourt. An unpublished M.Sc Dissertation, submitted to the department of Geography and Environmental Management, University of Port Harcourt.
2. Oluocha NO, Okeke IC (2004) Implications of wetlands, degradation for water resources management: lessons from Nigeria. Geojournal 16(2): 151-154.

3. Asibor G (2009) Wetlands: values, uses and challenges. A paper presented to the Nigerian environmental society at the petroleum training institution. Nigeria.

4. Chidi OH, Ominigbo OE, (2010) Climate changes and coastal wetlands: Nigeria in perspective. International Journal of environmental issues $7(2): 21-223$

5. Millennium Ecosystems Assessment (2005) Ecosystems and human wellbeing: wetland and synthesis. World Resources.

6. Bonfis L, Pascale Braconnot, Nathalie de Noblet, Sylvie Joussaume (2001) Hot desert albedo and climate change: mid,' 1-tolocene monsoon in North Africa. International journal of climate change 4: 3724-3737.

7. Dietrich V (2005) Biodiversity and climate change Asian/institute of technology press.

8. Orji G, Pepple GT (2015) Wetland Inventory and Mapping for Ikorodu Local Government Area, Lagos. Sofia, Bulgaria, 17-21.

9. Obiefuna JN, Nwilo PC, Atagbaza AO, Okolie C (2013) Spatial changes in the wetlands of Lagos/Lekki. Journal of Sustainable Development vol 6.

10. Mitsch W, Gosselink JG, Tore Soderqvist, Kerry Turner R (2007) The values of wetlands: landscapes and institutional perspectives. Ecological Economics 35 (200) 25-33.
(C) This work is licensed under Creative

To Submit Your Article Click Here:

Submit Article

DOI: $10.32474 /$ AOICS.2018.02.000137

\section{AOICS}

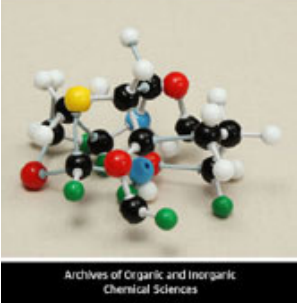

\section{Archives of Organic and Inorganic} Chemical Sciences

\section{Assets of Publishing with us}

- Global archiving of articles

- Immediate, unrestricted online access

- Rigorous Peer Review Process

- Authors Retain Copyrights

- Unique DOI for all articles 